\title{
EXTRACORPOREAL MEMBRANE OXYGENATION FOR ACUTE RESPIRATORY AND CARDIAC FAILURE
}

\author{
Hideshi ITOH ${ }^{1,2,4^{*}}$, Nguyen The Binh ${ }^{2,3}$, Le Ngoc Thanh ${ }^{2,3}$, Hitomi Ando ${ }^{1}$, \\ Naohiro Inagawa ${ }^{4}$, Shingo Ichiba ${ }^{5}$
}

\section{ABSTRACT}

Extracorporeal Membrane Oxygenation (ECMO) is widely used for acute respiratory and cardiac failure in critical situations as mechanical circulatory and respiratory support systems. Historically, ECMO had been two arguments both for and against using in critical situation. Despite the widespread adoption of ECMO in critical situation, the use of ECMO remains associated with significant morbidity and mortality. In 2019, an outbreak of pneumonia caused by severe acute respiratory distress syndrome (ARDS) by corona virus 2 (SARS-CoV-2) has occurred in China. SARS-CoV-2 has rapidly spread out the community of whole over the world, and cause severe respiratory failure disease (COVID-19) associated mortality and lack of immunization and treatment. According to the interim guidance formulated by the World Health Organization (WHO), ECMO should be considered as a rescue therapy or COVID-19 with refractory hypoxemia despite lung protective ventilation. The focus of this review will be on the physiological aspects of respiratory and cardiac ECMO.

Keywords: ECMO, ARDS, Cardiac Failure, Respiratory Failure, COVID-19, SARS

\section{Introduction}

Extracorporeal Membrane Oxygenation (ECMO) is widely used for acute respiratory and cardiac failure in critical situations as mechanical circulatory and respiratory support systems. In 1972, Hill JD et al. reported the successful use of ECMO on acute respiratory distress syndrome
(ARDS) (1). Early ECMO treatment had marked by both success and failure. In 1979, Zapol WM et al. reported the first randomized trials of ECMO sponsored by the National Institute of Health (NIH) from 1974 to 1977, ECMO was compared to conventional treatment in adults with ARDS (2). The results on this trial showed that both groups were only $9 \%$ survival rates. In ECMO group, thrombus formation and fibrosis of micro vessels in the lungs remarkably recognized. This trial had stopped by their high mortality rates. There were many problems with the trial, including prolonged mechanical ventilation over 9 days before introduction of ECMO, uncontrolled bleeding, the predominance of influenza pneumonia in enrolled patients and the lack of prior ECMO experience by some of the centers involved. The results brought us the improvement of patient selections and ECMO technology, it led the disappearances of choice of ECMO to treat adult respiratory failure for decades. In generally, the risks of being on ECMO are bleeding, kidney failure, infection, leg damage and strokes.

1 Department of Biomedical Engineering, Nippon Bunri University Graduate School of Engineering, Oita, Japan

2 University of Medicine and Pharmacy, Vietnam National University, Hanoi, Viet-Nam

3 Cardiovascular Center, E Hospital, Hanoi, Viet-Nam, Hanoi

4 Department of Mechatronics Engineering, Nippon Bunri University Graduate School of Engineering, Oita, Japan

5 Department of Clinical Engineering, Tokyo Women's Medical University Hospital, Tokyo, Japan

${ }^{*}$ Corresponding author. Prof. Hideshi ITOH

Email address: itohs@nbu.ac.jp

Received: 11 May $2021 \quad$ Accepted: 02 July 2021 
On the other hands, in 1976, Bartlett et al. reported the successful use of ECMO for a neonatal patient with respiratory failure, since then, ECMO has been used effectively for a variety of indications, including preoperative hemodynamic support, low cardiac output after cardiopulmonary bypass (CPB), sudden cardiac arrest, and as a bridge to heart transplantation especially in neonatal and pediatric fields (3-7). The results of the CESER trial (conventional ventilatory support versus extracorporeal membrane oxygenation for severe adult respiratory failure) were encouraging (8). The ARDS is associated with high mortality despite the use of low-volume, low pressure ventilation strategies that are aimed at reducing ventilatedinduced lung injury (VILI) (9). Therefore, ECMO had been two arguments both for and against using in critical situation before using ECMO for influenza A (H1N1 2009) associated with ARDS (10-13). Behind the improvement of the ECMO treatment outcomes, avoiding highflow ECMO management (full-flow support), high-pressure high-concentration oxygen administration management during mechanical ventilatory support.

According to the Extracorporeal Life Support Organization (ELSO) registry report, ECMO has been used over 133, 371 cases and 68,814 cases for respiratory ECMO, 40,733 cases for cardiac ECMO of them in July 2020 since 1990. The current reported survival and discharged rate for neonatal respiratory failure is $73 \%$, for pediatric respiratory failure $60 \%$, for adult respiratory failure $60 \%$, for neonatal cardiac failure $43 \%$, for pediatric cardiac failure $53 \%$, for adult cardiac failure $44 \%$ (14).

In 2019, an outbreak of pneumonia caused by severe acute respiratory distress syndrome
(ARDS) by corona virus 2 (SARS-CoV-2) has occurred in China (15-17) SARS-CoV-2 has rapidly spread out the community of whole over the world, and cause severe respiratory failure disease (COVID-19) associated mortality and lack of immunization and treatment. According to the interim guidance formulated by the World Health Organization (WHO), ECMO should be considered as a rescue therapy or COVID-19 with refractory hypoxemia despite lung protective ventilation $(15,18)$. From this kind of circumstances, ECMO has been establishing a treatment of respiratory support in critical organs failure on these days. On this review, we review about ECMO for acute critical respiratory and cardiac failure as a mechanical circulatory and respiratory support especially focus on physiological aspects of ECMO.

\section{Respiratory ECMO}

The primary indications for respiratory ECMO using veno-venous ECMO (VV ECMO, Figure 1) in acute respiratory failure include hypoxemic respiratory failure, hypercarbic respiratory failure, respiratory failure in lung transplant, bronchopleural fistulas and pulmonary air leaks and complex airway management (19). The goal of VV ECMO is to provide adequate oxygenation and $\mathrm{CO}_{2}$ removal for the patient. Veno-venous cannulation (VV canulation) provides an alternative means of extracorporeal support for patients with severe respiratory failure who do not require cardiac support. If the patient's circulation is stable without high-dose inotrope therapy and echocardiography does not show right ventricular or left ventricular failure, VV ECMO should be selected (20). VV cannulation utilizes a major vein for blood drainage and a vein for return of oxygenated blood to the right side of the heart. It is usually 
select as the blood return site, the right atrium, forward through the pulmonary circulation (25). pulmonary arteries, or internal jugular vein. The four primary affecting recirculation are the Generally, VV ECMO is established with 21-25 French draining and 15-19 French returning cannula in adults using femoral approach with modified Seldinger's technique $(21,22)$. VV ECMO is performed using two general approaches to cannulation and delivery of flow, with either two separates drainage and return cannulas (two-site VV ECMO) or a single double lumen catheter (DLVV ECMO) (23). A dual lumen cannula is inserted via the right jugular vein and drain from SVC and lower RA and reinfuse in the middle of RA towards the tricuspid valve, this cannula design is common in neonatal ECMO and will cause a variable degree of recirculation. (24). Recirculation occurs when returned blood is withdrawn through the access cannula rather than flowing site of the heart.

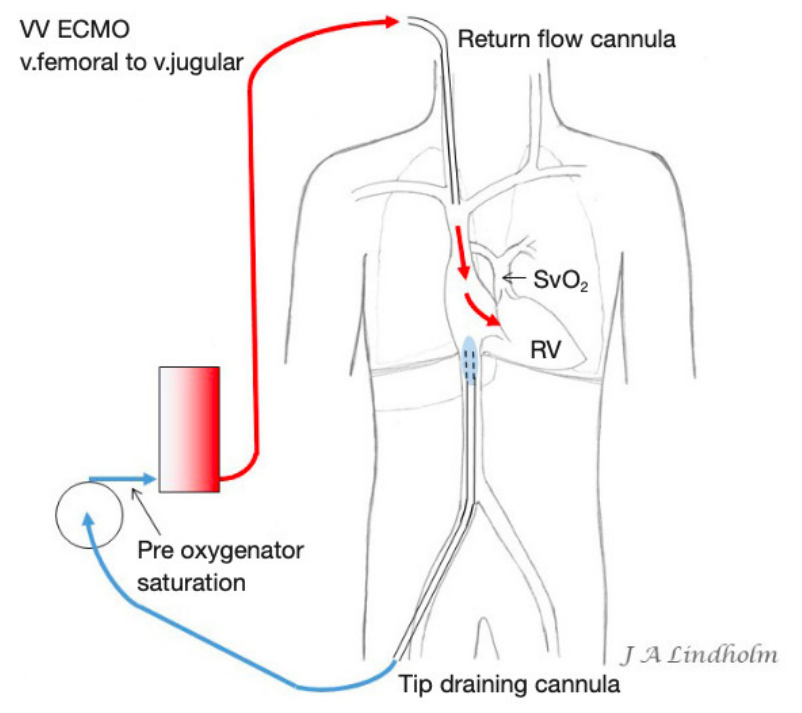

Figure 1. VV ECMO

VV ECMO draining in IVC and returning in right jugular vein. VV: Veno-Venous, ECMO: Extracorporeal Membrane Oxygenation, RV: right ventricle, IVC: inferior vena cava. Modified. (Lindholm JA. Cannulation for veno-venous extracorporeal membrane oxygenation. J Thorac Dis 2018; 10(5): S606-S612.) 

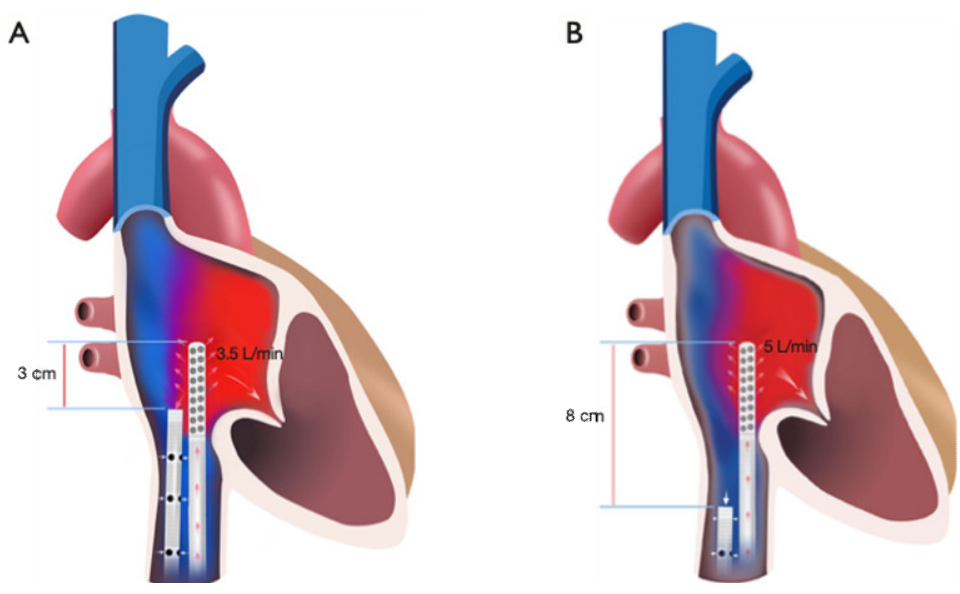

Figure 2. Femoral Cannulations

Recirculation during fem-fem VV-ECMO

(A) Inadequate separation of access and return cannulas can lead to high recirculation

(B) Adequate separation of access and return cannulas will reduce recirculation. VV ECMO, veno-venous extracorporeal membrane oxygenation.

Modified. (Burrell AJC, Ihle JF, Pellegrino VA, Sheldrake J, Nixon PT. Cannulation technique: femoro-femoral. J Thorac Dis. 2018;10: S616-S623)

\section{Cardiac ECMO}

Cardiac ECMO is powerful circulatory support as a lifesaving system. It is used for cardiogenic shock, refractory cardiac arrest, postoperative refractory cardiac, procedural support and bridge to lung or heart transplantation (28-30). Cardiogenic shock and cardiac arrest are critical situation with a high mortality rate despite numerous efforts in diagnosis and therapy. While ECMO is lifesaving, morbidity is common and both bleeding and thrombosis are associated with worth outcome (31).

Generally, on cardiac ECMO, veno-arterial ECMO (VA ECMO, Figure 3) is selected to support circulatory and respiratory in critical situations. VA ECMO circuits consist of a venous (inflow, drainage) cannula, a centrifugal pump, an oxygenator, and arterial (outflow, return) cannula (30). VA ECMO drains blood from the right atrium and returns to the arterial systems, typically to the iliac arteries toward to the aorta (Figure 3). By this, VA ECMO reduces preload and increases aortic flow and end organ perfusion (31). At the same time, retrograde flow support increases LV afterload. Moreover, the retrograde flow support of VA ECMO would cause severe LV distention and pulmonary edema. VA ECMO is associated with the potential risk of major limb vessels occlusion by the arterial cannula, as well as arterial embolism and refractory cannula site bleeding (20). With arterial cannulation, placement of a dedicated sheath for antegrade perfusion of the cannulated leg is recommended to prevent leg ischemia (32). When considering ECMO support, it is important to note that ECMO is only a support modality and does not treat the primary disease causing cardiac and respiratory 
dysfunction. Hence, Cardiac ECMO is most useful for those patients whose primary disease is reversible or can be successfully treated and associated with good prognosis. Recently, there have been some discussion on initiating mechanical support even earlier, with the intention to avoid multi organs failure associated with excessive catecholamine doses and/or aggressive ventilator setting (29, 34). Vasopressors increase myocardial afterload and potentially impair peripheral tissue perfusion. Thus, from a pathophysiological perspective, inotropes as well as vasopressors are associated with adverse effects on the heart and other end organs while these organs should recover (29). In clinical routine, catecholamines are often effective in terms of increasing blood pressure, but linked to impaired microcirculation and multi organs failure, and thus not sufficient for sustained and harmless stabilization patients with severe cardiac failure (29). We have been recommended the aggressive ECMO which is defined as commencement of ECMO as early as possible before end-organ dysfunction or complete circulatory collapse, and without hesitation for the introduction of ECMO (6). The goals of cardiac ECMO are to provide adequate flow to match the patient's metabolic demand and myocardial rest while protecting end organ perfusion such as lung rest during respiratory ECMO support.

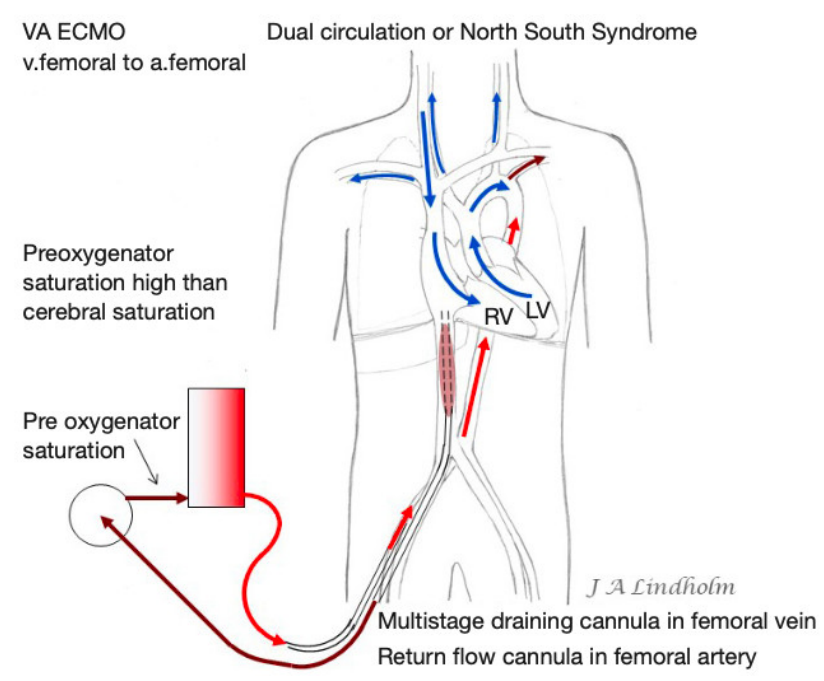

Figure 3. V-A ECMO

$\mathrm{V}-\mathrm{A}$ ECMO draining in IVC and returning in femoral artery with pulmonary blood flow but without gas exchange within the lungs.

V-A: Veno-Arterial, ECMO: extracorporeal membrane oxygenation, IVC: inferior vena cava.

Modified. (Lindholm JA. Cannulation for veno-venous extracorporeal membrane oxygenation. J Thorac Dis 2018; 10(5): S606-S612.)

\section{Physiological Aspects of ECMO}

During VA ECMO, we need to know the dilemma of VA ECMO support (Figure 4). As common clinical issues, we infuse to maintain
ECMO flow. It brings us the increasing of pulmonary blood flow. After increasing of pulmonary blood flow, it causes LV dysfunction due to mismatch of LV preload and afterload. 
Another, it causes ECMO Lung (ECMO lung means that a chest X-ray show the whitening shadow due to worsening pulmonary function, mostly caused by pulmonary edema, after commencement of ECMO.) When it occurs, both $\mathrm{LV}$ disfunction due to mismatch of LV preload and afterload or ECMO lung, we reduce perfusion flow of ECMO. It leads worsening of ECMO lung, or systemic organs edema caused by increasing of central venous pressure (CVP), or organs ischemia caused by poor systemic perfusion flow of ECMO. Once systemic organs edema caused by increasing of CVP happens, we increase the perfusion flow of ECMO. If organs ischemia caused by poor systemic perfusion flow happens, we increase perfusion flow of ECMO or infusion to maintain systemic ECMO flow. When we infuse to maintain ECMO flow, it will lead systemic organs edema. Otherwise, when it occurs LV dysfunction due to mismatch of LV preload and afterload, we will increase ECMO flow. Both ending to treat LV dysfunction due to mismatch of LV preload and afterload, it leads over volume control of ECMO to keep best perfusion flow of ECMO, is LV dysfunction due to mismatch of LV preload and afterload again. Finally, it may lead non-survive of ECMO. Moreover, worsening of ECMO lung caused by reducing of ECMO flow leads severe respiratory failure. And, organs ischemia caused by poor systemic perfusion flow may lead multiple organs failure (MOF). Both severe respiratory failure or MOF lead non-survive of ECMO.

Realization of left ventricular (LV) distention and pulmonary edema during $\mathrm{V}-\mathrm{A}$ ECMO is important for treatments. The presence and degree of aortic valve opening can be detected on the arterial pulse pressure tracing. Mean arterial pressure increases with increasing
ECMO flow, but pulse pressure and stroke volume decrease, reflecting decreasing aortic valve opening (30). It is useful using cardiac echocardiography to evaluate of $\mathrm{LV}$ distention and to assess change in LV dimension. A chest $\mathrm{x}-$ ray can signify worsening pulmonary capillary wedge pressure (PCWP) to assess pulmonary edema. The pulmonary artery catheter (SwanGanz Catheter) in site and measure either the pulmonary artery diastolic pressure or PCWP is the best way to know LV filling pressure and assess LV distention and pulmonary edema during VA ECMO.

There are several strategies for LV unloading during VA ECMO such as inotropes, vasodilators, Intra-Aortic Balloon Pumping (IABP), balloon atrial septostomy, LA-AO cannula connected to venous port of ECMO circuit, surgical LV vent, percutaneous LV vent, percutaneous ventricular support, off-pump central VA ECMO and continuous hemodialysis connected in the ECMO circuit. Each option has own advantages and limitations $(30,35)$.

Retrograde ECMO flow during peripheral approach that from the femoral or iliac artery back toward the thoracic aorta, blood travels unnatural direction it makes opposite ECMO flow direction. In this case, there is an area of watershed which is the region within the aorta where the two blood streams meet (35). This watershed region can lie anywhere between the aortic root and diaphragm depending on the output of the LV relative to ECMO flow. The level where the watershed depends on the relative pressures and flows in both systems. The oxygen content of the blood coming from the left ventricle is unknown, posing a risk of profound hypoxemia to the heart and the brain when the watershed is located distal from the carotids (35). 
If the watershed region is located distal to the left subclavian artery, there may be considerable risk of profound hypoxemia to the brain, heart, and upper extremities. In extreme circumstances, this may lead to Harlequin syndrome, also known as north-south syndrome (30).

Because of these reasons, ECMO have their own problems especially LV dysfunction dur to mismatch of LV preload and afterload, and to solve these issues might be brings us better clinical outcomes and it impact on ECMO treatments. One way to solve these issues of the dilemma of ECMO, we recommend to use the pulsatile ECMO with centrifugal pump system. Our study demonstrated that pulsatile ECMO produce significantly higher hemodynamic energy and improves systemic microcirculation associated with an increase in nitric oxide and it causes the systemic vasodilation by diffusing into vascular smooth muscle cell (28). Nitric oxide secretion from the endothelium is stimulated by the mechanical shear stress of pulsatile flow acting on vessel endothelium. Synchronized pulsatile ECMO flow with the heart rhythm lowering systolic VA ECMO output on the LV ejection fraction and PCWP after circulatory failure following cardiac arrest (36).

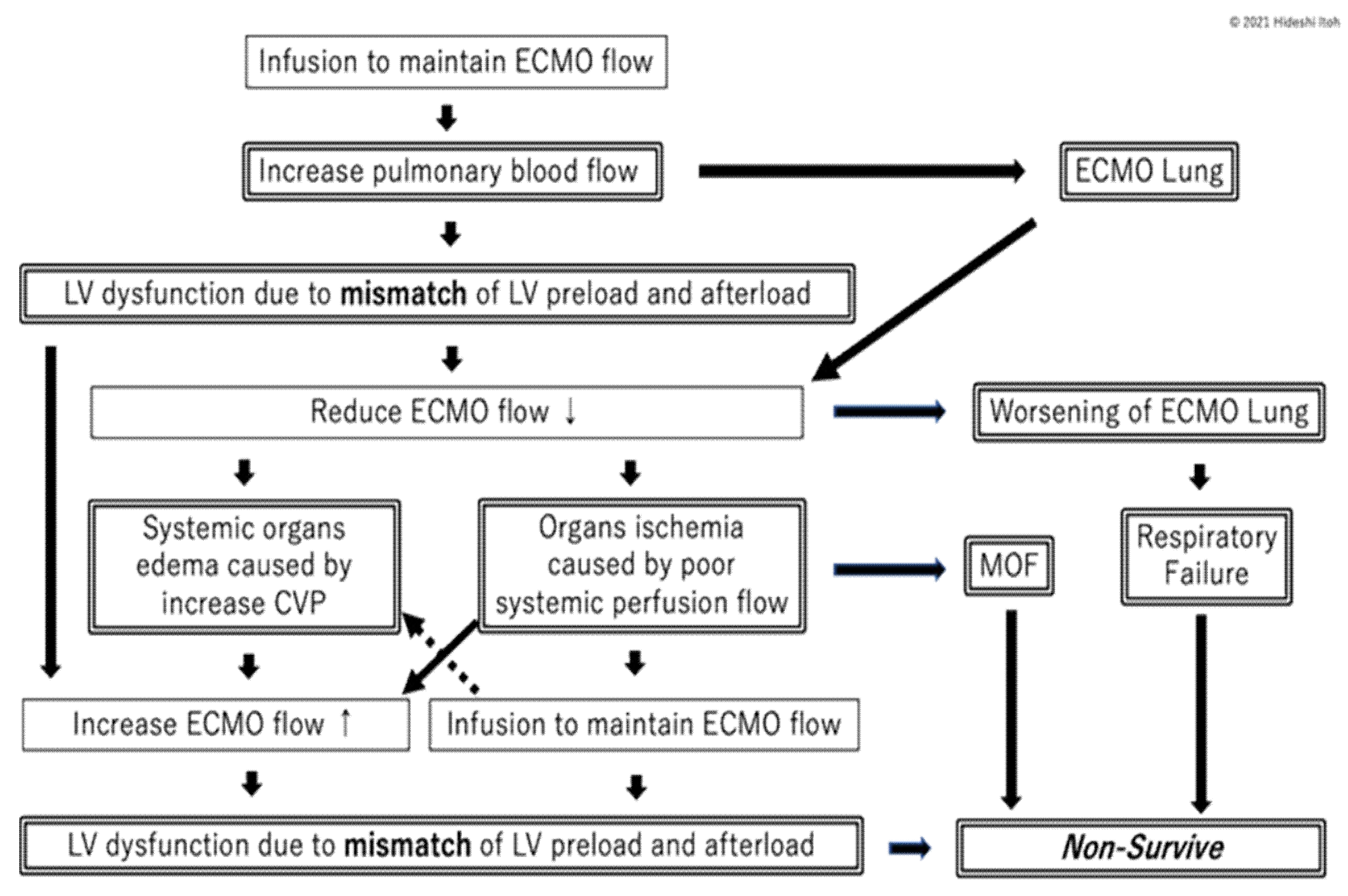

\section{SUMMARY}

Overall, we should strive for better outcomes with this ECMO treatment in critical situations. Technical improvements and team

Figure 4. Dilemma of ECMO

managements might have been contributed to the current and future worldwide use of ECMO for severe respiratory and cardiac failure refractory to medical treatments. We have been believing 
ECMO might be help to prepare and plan provision of ECMO not only dairy clinical use for acute respiratory and cardiac failure, but also during the ongoing pandemic such as COVID-19.

\section{REFERENCES}

1. Hill JD, O’Brien TG, Murray JJ, Dontigny L, Bramson ML, Osborn JJ, Gerbode F. Prolonged extracorporeal oxygenation for acute post-traumatic respiratory failure (shock-lung syndrome). Use of the Bramson member lung. $N$ Engl J Med 1972; 286(12): 629-34.

2. Zapol WM, Snider MT, Hill JD, et al. Extracorporeal membrane oxygenation in severe acute respiratory failure. A randomized prospective study. JAMA 1979; 242: 2193-6.

3. Bartlett RH. Esperanza. Presidential address. Trans Amer Soc Artif Intern Organs 1985; 31: 723-6.

4. Bartlett RH, Andrews AF, Toomasian JM, et al. Extracorporeal membrane oxygenation for newborn respiratory failure: forty-five cases. Surgery 1982; 92: 425-33.

5. O'Rourke PP, Crone RK, Vacanti JP, et al. Extracorporeal membrane oxygenation and conventional medical therapy in neonates with persistent pulmonary hypertension of new born: a prospective randomized study. Pediatrics 1989; 84: 957-63.

6. Itoh H, Ichiba S, Ujike Y, Kasahara S, Arai $\mathrm{S}$, Sano S. Extracorporeal membrane oxygenation following pediatric cardiac surgery: development and outcomes from a single-center experience. Perfusion 2012; 27(3): 225-29.
7. Booth KL, Roth SJ, Laussen PC, et al. Extracorporeal membrane oxygenation support of the Fontan and bidirectional Glenn circulations. Ann Thorac Surg 2004; 77: 1341-48.

8. Peek GJ, Clemens F, Elbourne D, Firmin R, Hardy P, Hibbert C, Killer H, Mugford M, Thalanany M, Tiruvoipati R, Truesdale A, Wilson A. CESAR: conventional ventilatory support vs extracorporeal membrane oxygenation for severe adult respiratory failure. BMC Health Serv Res 2006; 6:163. doi: 10.1186/1472-6963-6-163.

9. Thompson BT, Chambers RC, Liu KD. Acute Respiratory Distress Syndrome. $N$ Engl J Med 2017 Aug 10;377(6):562-572. doi: 10.1056/NEJMra1608077.

10. Peek GJ, Moore HM, Moore $\mathrm{N}$ et al. Extracorporeal membrane oxygenation for adult respiratory failure. Chest 1997; 112:759-64.

11. Laforte A, Walter EMD, Hetzer $\mathrm{R}$ et al. Extracorporeal membrane oxygenation for intraoperative cardiac support in children with congenital heart disease. Interact Cardio Vasc Thorac Surg 2010; 10: 753-758.

12. Lewandowski K, Rossaint R, Pappert D et al. High survival rate in 122 ARDS patients managed according to a clinical algorithm including extracorporeal membrane oxygenation. Intensive Care Med 1997; 23: 819-35.

13. Millar JE, Fanning JP, McDonald CI, McAuley DF, Fraser JF. The inflammatory response to extracorporeal membrane oxygenation (ECMO): a review of the pathophysiology. Crit Care 2016; 20:387. 
14. Extracorporeal Life Support Organization Registry report. ELSO. 2020.

15. https://www.who.int/csr/don/12-january2020-novel-coronavirus-china/en. Accessed 3 Apr 2020.

16. Kowalewski M, Fina D, Słomka A, Raffa GM, Martucci G, Lo Coco V, De Piero ME, Ranucci M, Suwalski P, Lorusso R. COVID19 and ECMO: the interplay between coagulation and inflammation-a narrative review. Crit Care 2020; 24(1):205.

17. Hartman ME, Hernandez R, Patel K, Wagner TE, Trinh T, Lipke AB, Yim ET, Pulido JN, Pagel JM, Youssef SJ, Mignone JL. COVID19 Respiratory Failure: Targeting Inflammation on V-V ECMO Support. ASAIO J 2020: 1-4.

18. Shekar K, Badulak J, Peek G, Boeken U, Dalton HJ, Arora L, Zakhary B, Ramanathan K, Starr J, Akkanti B, Antonini MV, Ogino MT, Raman L, Barret N, Brodie D, Combes A, Lorusso R, MacLaren G, Müller T, Paden M, Pellegrino V; ELSO Guideline Working Group. Extracorporeal Life Support Organization Coronavirus Disease 2019 Interim Guidelines: A Consensus Document from an International Group of Interdisciplinary Extracorporeal Membrane Oxygenation Providers. ASAIO J. 2020 Jul;66(7):707-721.

doi:10.1097/MAT.0000000000001193.

19. Sen A, Callisen HE, Alwardt CM, Larson JS, Lowell AA, Libricz SL, Tarwade P, Patel BM, Ramakrishna H. Adult venovenous extracorporeal membrane oxygenation for severe respiratory failure: Current status and future perspectives. Ann Card Anaesth 2016; 19: 97-111.
20. Aokage T, Palmer K, Ichiba S, Takeda S. Extracorporeal membrane oxygenation for acute respiratory distress syndrome. J Intensive Care. 2015 Jun 17; 3:17. doi: 10.1186/s40560-015-0082-7

21. Burrell AJC, Ihle JF, Pellegrino VA, Sheldrake J, Nixon PT. Cannulation technique: femoro-femoral. J Thorac Dis. 2018;10: S616-S623.

22. Patel AR, Patel AR, Singh S, Singh S, Munn NJ. Venovenous Extracorporeal Membrane Oxygenation Therapy in Adults. Cureus. 2019 Aug 11;11(8): e5365. doi: 10.7759/cureus.5365.

23. Makdisi G and Wang IW. Extra Corporeal Membrane Oxygenation (ECMO) review of a lifesaving technology. J Thorac Dis 2015; 7(7): E166-E176.

24. Lindholm JA. Cannulation for veno-venous extracorporeal membrane oxygenation. $J$ Thorac Dis 2018; 10(5): S606-S612.

25. Abrams D, Bacchetta M, Brodie D. Recirculation in venovenous extracorporeal membrane oxygenation. ASAIO J. 2015;61(2):115-21.

26. Yastrebov K, Kapalli T, Manganas $\mathrm{C}$. Semiquantification of Systemic Venous Admixture During Venovenous Extracorporeal Oxygenation Via Bicaval Double-Lumen Cannula in Critically Ill Patients. ASAIO J 2020; 66(1): 23-31.

27. Berdajs D. Bicaval dual-lumen cannula for venovenous extracorporeal membrane oxygenation: Avalon $\subset$ cannula in childhood disease. Perfusion 2015; 30(3):182-6.

28. Itoh H, Ichiba S, Ujike Y, Douguchi T, Obata H, Iwasaki T, Kasahara S, Sano S, Ündar A. Effect of the Pulsatile Extracorporeal 
Membrane Oxygenation on Hemodynamic Energy and Systemic Microcirculation in a Piglet Model of Acute cardiac Failure. Artif Organs 2016, 40(1): 19-26.

29. Napp LC, Kühn C, Bauersachs J. ECMO in cardiac arrest and cardiogenic shock. Herz 2017; 42(1):27-44.

30. Rao P, Khalpey Z, Smith R, Burkhoff D, Kociol RD. Venoarterial Extracorporeal Membrane Oxygenation for Cardiogenic Shock and Cardiac Arrest. Circ Heart Fail 2018; 11(9): e004905. doi: 10.1161/CIRCHEARTFAILURE.118.004905.

31. Napp LC, Kühn C, Hoeper MM, VogelClaussen J, Haverich A, Schäfer A, Bauersachs J. Cannulation strategies for percutaneous extracorporeal membrane oxygenation in adults. Clin Res Cardiol. 2016;105(4):283-96.

32. Rupprecht L, Lunz D, Philipp A, Lubnow M, Schmid C. Pitfalls in percutaneous ECMO cannulation. Heart Lung Vessel. 2015;7(4):320-6.

33. Cashen K, Meet K, Dalton HJ. Platelet Count and Function during Pediatric Extracorporeal
Membrane Oxygenation. Semin Thromb Hemost 2020;46(3):357-365.

34. Itoh H, Miyake Y, Hioki I, Tanaka S, Okabe M. Report of Takotsubo Cardiomyopathy Occurring During Cardiopulmonary Bypass. JECT 2007; 39:109-111.

35. Hoeper MM, Tudorache I, Kühn C, Marsch G, Hartung D, Wiesner O, Boenisch O, Haverich A, Hinrichs J. Extracorporeal membrane oxygenation watershed. Circulation 2014.130(10):864-5. doi: 10.1161/CIRCULATIONAHA.114.011677.

36. Voicu S, Sideris G, Dillinger JG, Yannopoulos D, Deye N, Kang C, Bonneau M, Bartos J, Kedra A, Bailliart S, PasteurRousseau A, Amah G, Bonnin P, Callebert J, Henry P, Megarbane B. Synchronized Pulsatile Flow With Low Systolic Output From Veno-Arterial Extracorporeal Membrane Oxygenation Improves Myocardial Recovery After Experimental Cardiac Arrest in Pigs. Artif Organs. 2018 Jun;42(6):597-604. doi: 10.1111/aor.13089. Epub 2018 Mar 6. 